\title{
The Combustion of Emulsified Glycerol-Heavy Oil Fuel Droplet
}

\author{
S. Soulayman ${ }^{*}$ and K. Youssef
}

Higher Institute for Applied Sciences and Technology, Damascus, Syria

\begin{abstract}
In this work the evaporation of the emulsified glycerol- heavy fuel oil (CG-HFO) droplets with different activator is modeled. The influence of activator gas bubbles volume developments on the evaporation of fuel droplets in the high temperature combustion chamber is studied. The crude glycerol as the secondary product of biodiesel production is used as the first component of the emulsion while the second component is heavy fuel oil. The crude glycerol contains methanol, aromatics, minerals, a little bit biodiesel and water. These materials were pressurized and injected in the chamber with three inputs: the first one is for the CG-HFO, the second one is for activator while the third one is for air for forming the emulsion and then passing to the combustion chamber. The applied pressure is determined according to contents which lead to flame stability of the primary formed emulation. A comparison of calculated results, basing on semi-empirical method, with experimental ones demonstrates the modeling acceptable accuracy.
\end{abstract}

Keywords: Crude glycerol, Heavy fuel oil, Activator, Theory, Experiment.

\section{INTRODUCTION}

As the biodiesel production is increasing exponentially, the crude glycerol (CG) generated in this process has also been generated in a large quantity. Therefore, the use of biodiesel in the energy sector involves the growth of waste production that without proper disposal can lead to environmental disaster. CG, which is the main byproduct of biodiesel production $(9-12 \%[1,2])$ and typically contains less than 65 wt \% glycerol, is the main component of this waste. CG contains a variety of elements, such as calcium, magnesium, phosphor or sulfur, originating from the primary oil. Larger quantity of sodium or potassium is also contained, coming from catalyst [3]. Owing to wide variety of triglycerides, alcohols, catalysts, and separation processes used in biodiesel production, CG composition varies widely [4] (glycerin $45-65 \%$, methanol 5-15\%, aromatics $0-10 \%$, mineral impurities 3-10\%, water 10-20\%). (50-60\% glycerin, $10-$ $30 \%$ methanol, $8-20 \%$ alkali catalyst that was consumed in saponification of free fatty acids, 5-15 soap formed from the catalyst and free fatty acid of the feedstock, up to $1 \%$ different polar components splitting from the feedstock [2]).

The investments for the construction and startup operation of CG purification facility were evaluated by Singhabhandhu [5]. Moreover, the amounts of the waste generated during the production of biodiesel exceed considerably the CG needs of the pharmaceutical and the cosmetic industries. So, to improve the economic feasibility of biodiesel industry,

*Address correspondence to this author at the Higher Institute for Applied Sciences and Technology, Damascus, Syria; Tel: +963999700803;

Fax: +963115134199; E-mail: soulayman.soulayman@hiast.edu.sy new alternate ways of utilization of CG should be studied. Therefore a real interest is expected in using waste glycerol as a boiler fuel to produce process steam and co-generate electricity. This application is primarily due to its relatively low cost and rapid production growth. A combined heat and power process that replacing fossil fuels and improving the economics of biodiesel production may be envisaged. If combined with biodiesel production, this has the added advantages of optimizing energy integration, eliminating transportation costs, and displacing the need for fossil fuels. However, due to its low energy density, high viscosity, and high auto-ignition temperature, glycerol is difficult to burn. Even though pure glycerol is known to have a moderate heating value $(16 \mathrm{MJ} / \mathrm{kg})$, it has not previously been used as a fuel. Glycerol has a very high activation energy resulting in an auto-ignition temperature of $370{ }^{\circ} \mathrm{C}$ as compared to $210^{\circ} \mathrm{C}$ and $280{ }^{\circ} \mathrm{C}$ for kerosene and gasoline, respectively.

In this context, in [6] CG was emulsified into fuel oil to address difficulties with ignition and sustained combustion. Emulsions were prepared with several grades of glycerin and two grades of fuel oil using direct and phase inversion emulsification. Scott et al. [7] combusted the glycerol-diesel emulsion in a naturally aspirated single-cylinder diesel engine and reported the thermal efficiency improvements at high loads. Leng et al. [8] succeeded in obtaining stable nano-scaled glycerol-in-diesel micro-emulsion and glycerol/water-in- diesel micro-emulsion and concluded that micro-emulsion technology is promising fuelupgrading process for glycerol. Asdrubali et al. [9] focused their work on the development and the validation of a process to convert biodiesel- derived glycerol into a fuel for internal combustion engines and 
found that the use of these new oxy-fuels in diesel engines can lead to an effective reduction in terms of greenhouse gases emissions throughout the entire life cycle. In [10] a simple chamber for the combustion of the biodiesel residual glycerol was constructed and all parameters related to the combustion itself were evaluated. SAAKE Firm experiments show that glycerol combustion nature is dramatically different from other types of combustion of liquid fuels such as diesel fuel because of differences in their properties. The high density and the droplets surface tension adversely affect the quality of spraying.

The principal technological approach is hydrodynamic cavitation application to hydrocarbon fuels. The components of the emulsified fuels are initially mixed and then processed in special cavitation devices where homogenization, reactions and partial changing of fractional compositions of the end product are realized. The hydro-cavitation transformation development for emulsified fuels (including biofuels) ultra- dispersed spray and homogenization is an effective and inexpensive method to prepare waste materials for combustion. Because these composite fuels did not work well with current furnace spray nozzles, improved combustion nozzles were developed.

The CG-HFO combustion process takes place through the following steps: mixing of individual droplets of fuel with air, mixture heating and evaporation, thermal decomposition, the formation of gas phase ignition and completion of oxidation (combustion) of the gas phase. These stages are inseparable from each other, and they are combined at some way. Evaporation is a preparatory process during the combustion of liquid fuels. So, for combustion calculation, it is necessary to have data on fuel evaporation.

Evaporation of liquid fuels could be estimated using their rates of fractional composition and volatility (saturated vapor pressure, evaporation losses, etc.). The evaporation of fuel largely defines the operational parameters of the heat-generating units such as reliability, economic feasibility and durability of the work in different modes (for example, a light or labored start, fast or slow heating, fuel pick-up, combustion completeness, nature of fuel combustion). Therefore, it is possible to lock the fuel supply system (likely to affect emergency stop) and lower losses from fuel evaporation during storage [11]. Formed, after the passage of the first stages of the combustion, gas mixture is highly flammable and burns quickly. The fine spray of fuel particles and their uniform distribution increase the reaction active surfaces, facilitate heating and evaporation of the particles and help in making the combustion rapid and complete. Thus, in the combustor, fuel atomization is widely used and its further vaporization leads to the formation of a combustible mixture. Therefore, for the calculation of a mixture formation, a considerable interest should be devoted to study the evaporation of droplets which form the spray cone of fuel.

In the case of stationary non-adiabatic evaporation from the body surface Spalding [12] proposed a mathematical model to calculate the convective heat flux. This method is based on the assumption that convective heat flux at non-adiabatic evaporation is proportional to the deviation of the actual surface temperature from its equilibrium temperature, which would be the surface temperature in an adiabatic process. Later on Spalding [13] described the time dependence of droplet diameter and got the evaporation time, $t_{\mathrm{ev}}$, at which the droplet diameter equals zero, and showed that $t_{e v} \sim\left(d_{o}\right)^{2}$. Thus, to reduce the evaporation time droplet diameter should be reduced.

In calculating the evaporation rate, Maclead [14] and Shuleikin [15] applied the kinetic theory of evaporation where the Maxwell velocity distribution of the molecules is supposed and the work of evaporation is supposed to be equal to the internal heat of vaporization (the latter is possible only under the condition that the kinetic energy of the molecules of vapor and liquid are equal). Later on, Shuleikin [16] derived the rate of evaporation with taking into account the molecules own volume.

A liquid droplet (in the context of evaporation/combustion study) can be classified into three categories based on its constituents. The first one is a pure component droplet which comprises a single component. The second one is a multi-component droplet which consists of two or more liquids (miscible or immiscible), and the third one is a nano-fuel droplet where solid nanoparticles are suspended in the liquid droplet. The understanding of physical processes and their consequences in the combustion of pure component fuel droplet is well established. An important characteristic of the process of evaporation of the droplets is a droplet evaporation rate which is determined by the conditions under which this process occurs [17]. Diffusion about the nature of the evaporation process leads to the conclusion that the rate of evaporation is determined by the difference vapor elasticity values at the surface of the droplets 
and in the environment. In turn, the vapor pressure at the droplet surface is determined by its temperature and, therefore, depends on the heat exchange with the environment and the physical properties of the liquid and the environment. Dimensionless Lewis number $L e=D / \alpha$ represents the similarity of concentration and temperature fields in a flow, where $D$ is the diffusion coefficient $\alpha=\lambda /\left(p C_{P}\right)$ and is the thermal diffusivity. The rate of evaporation is limited by the mass transfer processes when $L e<1\left(T_{\infty}-\right.$ small $)$ and by heat transfer processes when $L e>1\left(T_{\infty}-l \arg e\right)$.

It should be noted that in many cases, the evaporation of fuel droplets is calculated using Sreznevsky law [18] which states that at given ambient temperature, the square of the droplet diameter linearly decreases with time due to evaporation.

$d_{k}^{2}=d_{k 0}^{2}-k_{e v} t$

where is the droplet diameter at time $t=0$; the surface of evaporation decreases linearly with time:

$\frac{d\left(d_{s}^{2}\right)}{d t}=k_{e v}=$ const

The theory of multi-component liquid droplet evaporation takes all the assumptions of the theory of evaporation of pure liquids, taking into account the dependence of the saturated vapor pressure above the droplet on its composition. Because, during evaporation, surface layer depleted droplets, more volatile components, in the study of the kinetics of evaporation of the droplets of multi-component fluids, the problem of the external and internal process of vapor diffusion component liquid droplet from the center to its surface must be solved. Such rigorous formulation of the problem has not yet been solved. Dwyer [19] assumed that the concentration of components in the droplets does not change in the process of evaporation.

In the thermal analysis of droplets evaporation in the steady state environment, some researchers have used a non-stationary model (see for example, [2022]), other authors have used the stationary evaporation model (see for example, [23]), other authors have used the quasi-stationary evaporation model (see for example, [24-28]), and some authors introduced various amendments to the quasi-steady theory and take into account the thermal relaxation phenomenon. It is important to note that, the theory of quasi-stationary droplet evaporation gives significant errors in the values of evaporation rates at a time close to zero, leading to the erroneous conclusion that the infinite mass of vapor evaporating into space. Moreover, the quasi-stationary solutions, which are usually used for the external diffusion or heat conduction problem, inaccurately describe the distribution of concentrations and temperatures far from the surface of the droplet due to inaccuracies of these solutions leading to the absurd conclusion that an infinite amount of heat or substances accumulate in remote areas environment.

Despite these efforts it still seems that the experimental findings (see for example [29, 30]) diverge from the existing molecular modeling and simulation results. On the theoretical side, modeling of evaporation was made for a long time with the kinetic theory of gases, assuming a half-sided MaxwellBoltzmann velocity distribution function as a boundary condition for the evaporating gas based on the bulk liquid temperature and the corresponding saturated vapor density.

In another case, when the components concentrations inside the droplet leveled instantly and the kinetics of evaporation was determined by the laws of change of vapor pressure components to its composition. This theory could be applied in the case of emulsion evaporation.

With regard to evaporation and combustion of fuel droplets Kotake \& Okazaki [31] noted that, the process of evaporation does not lead to a quasi-steady state of mass and heat transfer at the droplet surface. Concerning combustion, the process approaches at its end to a quasi-steady state, though the values of the flame temperature and the ratio of the flame radius to the drop radius are much smaller than those of the quasi-steady theory. The initial condition of the surrounding air has a great influence on the process of evaporation and combustion. Abramzon \& Sirignano [32] proposed a model that includes the effects of variable thermo-physical properties, non-unitary Lewis number in the gas film, the effect of the Stefan flow on heat and mass transfer between the droplet and the gas, and the effect of internal circulation and transient liquid heating. Sazhin et al. [33] provided a comparative analysis of liquid and gas phase models for fuel droplets heating and evaporation and concluded that, the gas phase model, taking into account the finite thickness of the thermal boundary layer around the droplet, in the form suggested by Abramzon and Sirignano [32], predicts the evaporation time closest to 
the one based on the approximation of experimental data. Later on, Sazhin [34] noted that, models describing the effects of multi-component droplets need to be considered when modeling realistic fuel droplet heating and evaporation. However, most of these models are still rather complicated, which limits their wide application in computation fluid dynamics codes. Recently, Sazhin and Al Qubeissi [35] proposed new mathematical tools and approximations developed for the analysis of automotive fuel droplet heating and evaporation.

Since the evaporation and combustion of droplets are taking place in the combustion chambers they cannot be simulated without the knowledge of the laws of the evaporation of individual droplets. Thus, the knowledge of the characteristics of the process of single droplet evaporation and burning is of scientific and practical interest. For example, increasing the CGHFO droplet evaporation time is associated with an increase in the length of the flame tube of the combustion chamber and vice versa.

One of the most important steps in view of the burning droplet is the evaporation activation approach, since the fuel and CG-HFO pre-ignition requires the intensification of prior-flame process steps. The knowledge of the droplets evaporation laws is of great practical importance from the viewpoint of accelerating the process of mixture forming, including gas activators.

However foam droplets evaporative must consider the process of droplet outer diameter growth at the first stage of the evaporation which takes place as a result of the more volatile component evaporation inside, and a sharp decrease in the mass and diameter in collapsing droplets when gas bubbles are pulled out.

The primary goal of the present work is to investigate the evaporation of liquid composite fuel CGHFO droplets with different activators experimentally and theoretically. The emulsified CG-HFO fuels, on the base of crude glycerol for combustion processes containing crude glycerol, heavy fuel oil and other combustible material for effective firing in power plants are created.

\section{EXPERIMENTAL SETUP}

The main components of the studied materials are crude glycerol (CG) generated by homogeneous basecatalyzed transesterification in a pilot production unit of $400 \mathrm{l} / \mathrm{day}$. Chemical analysis shows that the used
CG consisted of $59.7-62.21 \%$ glycerol, $12.4-12.59 \%$ alkali soaps, $1.32-1.47 \%$ sodium, $22-23.55 \%$ methanol, $1-1.3 \%$ water and $2-2.5 \%$ biodiesel. The CG lodine value is $13.57-14.69(\mathrm{gl} / 100 \mathrm{~g})$ and the average density is $1.037\left(\mathrm{~g} / \mathrm{cm}^{3}\right)$. This analysis is in accordance with available data [3]. As CG is a cheap and low-quality fuel, it requires conversion to a better fuel that can compete with conventional fuel oil. In order to increase the CG calorific value a certain amount of heavy fuel oil (HFO) is added. Different gaseous fuels such as propane, methane, hydrogen and biogas were added also. Pure glycerin and HFO as reference materials are studied also. The chemical-physical properties of the used HFO are given in Table 1. When comparing the provided values with those provided in [36] one can conclude that, the used HFO is similar to class B [36] with respect to the specific gravity, flash point, ash content and sulphur content. Thus, it is of interest to compare the results of temperature-time histoire of used HFO in the present work with those of [36] but because of incorrectness of the provided extrapolation function in [36] the comparison is not feasible. Moreover, the emulsified HFO with water $(10 \%$ and $25 \%$ ) was studied in [37]. Therefore, it is reasonable to compare our results with those of [37].

Table 1: The Chemical-Physical Properties of the used HFO

\begin{tabular}{|c|c|c|}
\hline Property & Unit & Value \\
\hline \hline Density at $15{ }^{\circ} \mathrm{C}$ & $\mathrm{kg} / \mathrm{m}^{3}$ & 963.2 \\
\hline Flash point & ${ }^{\circ} \mathrm{C}$ & 100 \\
\hline Kinematic Viscosity at $80{ }^{\circ} \mathrm{C}$ & $\mathrm{mm}^{2} / \mathrm{s}$ & 8 \\
\hline Pour point & ${ }^{\circ} \mathrm{C}$ & 21 \\
\hline Water and sediments & $\% \mathrm{v}$ & 0.2 \\
\hline Asphaltenes & $\% \mathrm{wt}$ & 8 \\
\hline Total sulphur & $\% \mathrm{wt}$ & 3.36 \\
\hline Vanadium & $\mathrm{ppm}$ & 120 \\
\hline Sodium & $\mathrm{ppm}$ & 25 \\
\hline Total sediments & $\% \mathrm{wt}$ & 0.15 \\
\hline Ash & $\% \mathrm{wt}$ & 0.04 \\
\hline
\end{tabular}

Experiments were performed on suspended, isolated droplets. The captive droplet technique has been chosen here because it enables droplet behavior to be monitored over the whole period of heat treatment inside an enclosure where radiation is the dominant mode of heat transfer. A spherical furnace, a high-speed video system and an image processing system integrate the experimental set-up. The heated 
enclosure consists of two hemispheric sections built of aluminum such that they form a spherical furnace with a $200 \mathrm{~mm}$ internal diameter and $15 \mathrm{~mm}$ thickness. The furnace has two diametrically opposed view ports. One section of the furnace rests on a carrier that allows free movement in order to close the furnace. A filament with the single suspended droplet is introduced through one view port, while the high-speed video camera is located at a certain distance from the opposite viewport so that the suspended droplet can be filmed. A $1000 \mathrm{~W}$ tungsten filament lamp is positioned into the hollow furnace displaced $15 \mathrm{~mm}$ from the sphere's center. The lamp is connected to a voltage control unit that supplies the energy required to control the furnace temperature. The droplet is centered at the physical origin of the furnace. The radiant energy of the lamp is concentrated on the droplet by the polished interior surfaces. Because of the geometry of the sphere, any energy that bypasses the droplet is reflected back and the net result is that the droplet is heated from every side.

Droplet temperature is measured with a $0.05 \mathrm{~mm}$ diameter, Pt/Pt-13\%-Rh thermocouple. Its reference junction is inserted into an ice bath to maintain the temperature at $0.4^{\circ} \mathrm{C}$. To monitor the thermal history of the combustion process, the end wire of the thermocouple is connected to an oscilloscope and the millivoltage is measured. The corresponding temperature values are obtained from standard voltage -temperature charts. The recording system consists of a high-speed video camera (Kodak Ektapro 1000), an image processor, and a high-resolution monitor. The video camera films droplet activity from the time the droplet is placed into the furnace until the carbonaceous residue is oxidized. The video signal is transmitted to an image processor where the image is shown in the high-resolution monitor and, simultaneously recorded in a video recorder for analysis.

For gas bubble distribution and thermometric studies several samples of CG-HFO fuel were prepared with different percentages of components (mainly, crude glycerol and HFO). Samples were put in glass vials of $50 \mathrm{ml}$ and subjected to treatment in a blender with $15000 \mathrm{rpm}$ for 5 minutes. Since the CG is capable of foaming the resulting mixture in each sample contains air bubbles. Moreover, a mixer nozzle with three inputs is used. The first is for CG, the second is for activator while the third is for air for forming the emulsion, foaming and passing it to the combustion chamber. At the outlet from the injector-mixer, the CGHFO droplet includes gas bubbles activator. The gaseous bubbles in a CG-HFO fuel droplet were examined under a binocular microscope using digital camera Canon Power Shot S IS 2 in macro mode.

In the case of distilled water-HFO emulsified samples it was found that, the air bubbles were not observed and the emulsions were stable over a period of several months, which was judged by visual examination at room conditions. The distribution of the water droplets in the HFO were monitored several times within the stabilization period observing a dispersing homogeneous phase with water droplets of maximum diameter of approximately $5 \mu \mathrm{m}$ for all samples.

\section{EXPERIMENTAL RESULTS AND DISCUSSIONS}

\subsection{CG-HFO Droplet Heating Chronogram}

When evaporating emulsified fuel droplet with measuring its temperature (see Figure 1), it was observed the following: a) droplet warming; b) droplet volume growth up to the boiling point of low-boiling components; and c) droplet active boiling at which is the boiling temperature of crude glycerol. Temperature measurement error is $\pm 0.5^{\circ} \mathrm{C}$. The obtained result could be explained as follows: the initial emulsified fuel droplet has two phases: the dispersion medium CGphase and a dispersed phase - gas activator. During the droplet heating process, heat is transferred through the droplet dispersion medium to the dispersed gas activator, whereby, gas bubbles begin to expand and by continuing heating above the boiling point of methanol, $64.509{ }^{\circ} \mathrm{C}$, the methanol vapor forms microbubbles inside the droplet and a part of it accumulates inside the activator gas bubble thereby the droplet volume increases by increasing the micro-bubbles inside it, further heating of CG- phase causes the collapse of bubbles on the droplet surface announcing the moment of droplet stability loss (destruction).

\subsection{Water-HFO Droplet Heating Chronogram}

When evaporating the used HFO droplet and its emulsions with water with measuring the temperature of each of them, it was observed the following: a) for the HFO droplet only vapor around the droplet was observed during pre-ignition, indicating the presence of volatile compounds that form a visible cloud of vapors previous to ignition. When the vaporized components 


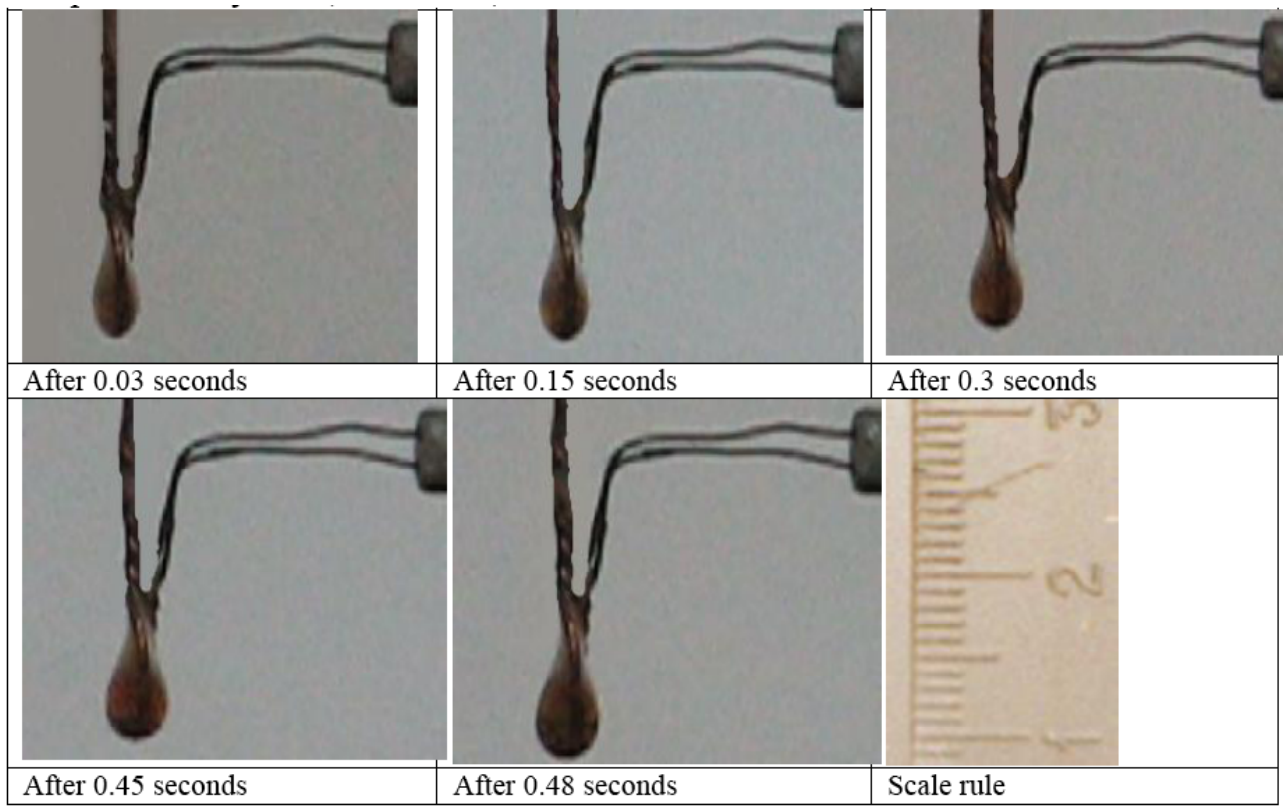

Figure 1: CG-HFO droplet heating chronogram.

mix with ambient air and when the temperature of the mixture reaches the critical ignition condition the droplet ignites and a visible flame appears; b) for the water-HFO droplet, the emulsion droplet had a large swelling produced by the vaporization of water droplets enlarging the droplet size considerably. Microexplosions followed releasing copious amounts of vapor accompanied by small droplets; c) the burning time of water-HFO droplet is smaller that of HFO by $25 \%$ approximately (see Figure 2 ).

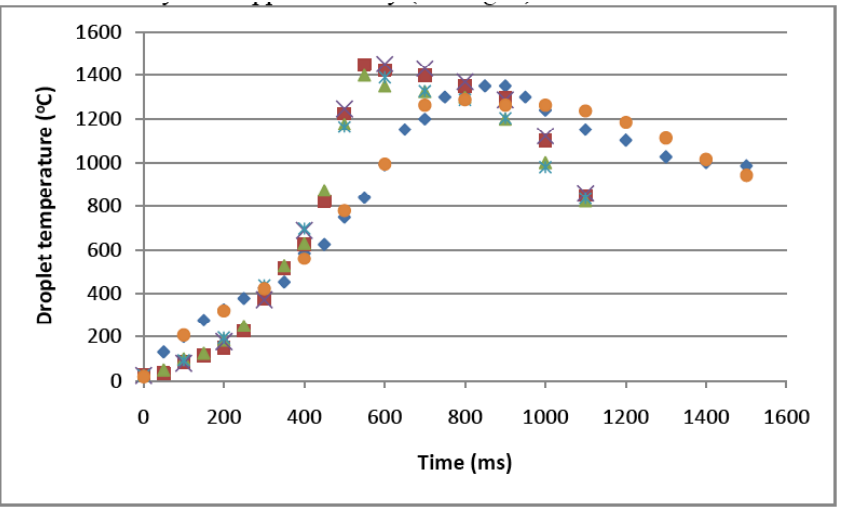

Figure 2: Time dependence of emulsified water-HFO fuel (घ for $10 \%$ and $\Delta$ for $25 \%$ water content) and HFO ( $\downarrow)$ droplet temperature. The results of [37] are denoted by $x$ for $10 \%$ and $*$ for $25 \%$ water content and by $\bullet$ for HFO.

It is seen from Figure 2 that a) the peak temperature of emulsions with $10 \%$ and $25 \%$ water occur much earlier in time than for the residual oil. The shift in the peak temperature is a measure of the effect of the water content in the emulsified water-HFO fuel and b) an important difference in the temperature transients between emulsions and HFO resides in the steep temperature gradients that emulsions show at the initial and final periods of combustion. This is an evidence of both soot reduction and the extent of burnout in the ambiance atmosphere, which is an important aspect in the reduction of pollutant emissions. These results are in a good agreement with those of [37] in spite of differences in HFO.

In [37], it is supposed that the time dependence of the measured droplet temperature could be described with a high accuracy by:

$$
\begin{aligned}
& T_{e 10}=3.05 \times 10^{-10} t^{5}-3.41 \times 10^{-7} t^{4}+1.37 \times 10^{-4} t^{3} \\
& -1.9 \times 10^{-2} t^{2}+1.346 t+20.92
\end{aligned}
$$

in the case of $10 \%$ water-HFO emulsion and by:

$$
\begin{aligned}
& T_{e 25}=8.44 \times 10^{-9} t^{4}-4.7 \times 10^{-6} t^{3} \\
& +4.53 \times 10^{-3} t^{2}+0.102 t+31.78
\end{aligned}
$$

in the case of $25 \%$ water-HFO emulsion. In Eqs (1) and (2) $T$ is in ${ }^{\circ} \mathrm{C}$ and $t$ is in s.

When calculating $T_{e 10}$ and $T_{e 25}$ using Eqs (1) and (2) it was found that the obtained values are illogic and do not coincide with the provided measured values (see Table 1 in [37]). In order to construct the suitable interpolation functions, the provided measured data in [37] were used in the present work. These functions have the following form: 
$T^{\prime}{ }^{1010}=-9.09858 \times 10^{-14} t^{6}+3.10317 \times 10^{-10} t^{5}-3.89283 \times 10^{-7} t^{4}+$ $2.11534 \times 10^{-4} t^{3}-4.40029 \times 10^{-2} t^{2}+3.54231 t+19.26$

$T^{\prime}{ }_{e 25}=-5.66313 \times 10^{-14} t^{6}+1.98244 \times 10^{-10} t^{5}-2.52693 \times 10^{-7} t^{4}+$ $1.36216 \times 10^{-4} t^{3}-2.65005 \times 10^{-2} t^{2}+2.35296 t+22.77$

When calculating the emulsified water-HFO fuel droplet temperature the Eqs (1) and (2) given in [37] and comparing the results with the provided in [37] experimental data, the results of Eq. (2) application are presented in Figure 3 while the results of Eq. (1) application are not included because of their big deviation from the corresponded experimental data. It is clear from Figure 3 that the application of Eq. (2) can lead to big errors. Thus, Eqs (1) and (2) could not be applied for predicting the emulsified fuel droplet temperature at different times of its development.

On the other hand, the application of the Eqs (3) and (4) leads to comparable results with experimental data (see Figure 4). It is clearly seen from Figure 4 that Eqs (3) and (4) describe the recorded temperature very well.

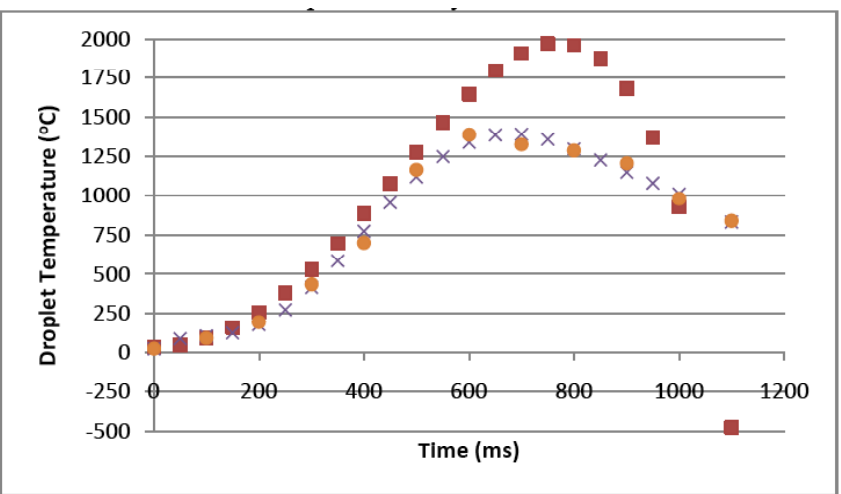

Figure 3: Temperature time dependence of the $25 \%$ waterHFO emulsified fuel droplet. - $\square$ and $x$ stand for measured data, calculated values using Eq. (2) and Eq. (4) respectively.

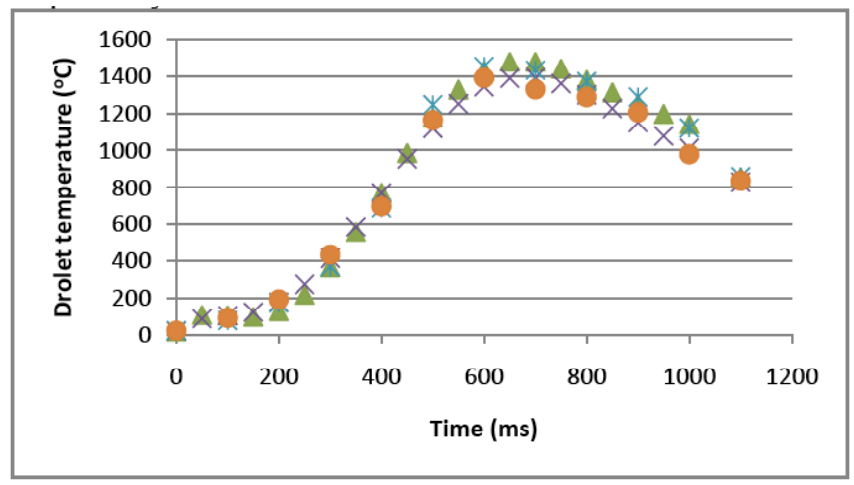

Figure 4: Temperature time dependence of the $10 \%$ and $25 \%$ water-HFO emulsified fuel droplet. $ж, \bullet, \Delta$ and $x$ stand for measured $10 \%$ \& $25 \%$ water data, Eqs (3) \& (4) values respectively.

\section{MATHEMATICAL MODELING}

The classical approach of predicting droplet evaporation rate is based on a purely diffusion controlled model where the details of molecular detachment at droplet surface are ignored, and the droplet surface is assumed to be in thermodynamic equilibrium with the adjacent vapor at saturated state. Accordingly, the evaporation rate is predicted to be the same as the rate of mass diffusion from droplet surface to ambient gas phase. The model is also known as hydrodynamic model. On the other hand, some of the recently used predictive tools are based on kinetic model and molecular dynamics model which take into account of non-equilibrium state at droplet surface along with the details of molecular detachment at the surface either by incorporating an empirical evaporation coefficient or by the analysis of molecular dynamics at liquid-gas interface [38].

However, when comparing different models of evaporation Sazhin et al. [33] noted that, the model based on the approximation of experimental data describe accurately the evaporation process. Therefore, the proposed semi-empirical mathematical model is developed on the basis of observed physical phenomena in regard to droplet heating and volume increase with the following approximations:

1. At the beginning, droplet contains gas activator only. The droplet form rests constant. This assumption takes place up to the moment of droplet stability loss.

2. All supplied heat to droplet is used for its evaporation.

3. The distribution of gas bubbles is homogeneous all over the time.

4. All bubbles have the same radius for each moment with an initial value $r_{b},(0)$. So, $d r_{b 1}=\cdots=d r_{b i}=\cdots=d r_{b n}$

5. The droplet surface temperature equal to the droplet volume temperature. So, the bubble temperature is equal to droplet temperature: $\mathrm{T}_{\mathrm{d}}(\mathrm{t})=\mathrm{T}_{\mathrm{b}}(\mathrm{t})=\mathrm{T}(\mathrm{t})$

6. CG components vapors (multi-component liquid) as well as gases inside bubbles are considered as perfect ideal gas with the same molar weight. The gases inside bubbles behave as a mixture of ideal gases. Even this approximation is 
disputative somehow, the calculated results will judge about its validity.

7. Droplet and bubbles Laplace pressure $P_{\sigma}$ could be neglected because at $20{ }^{\circ} \mathrm{C}$ the CG surface tension is $\sigma_{g f}=0.055 \mathrm{~N} / \mathrm{m}$ (for glycerin $\sigma_{g}=0.066 \mathrm{~N} / \mathrm{m}$ ) and the magnitude of the bubble Laplace pressure in $\mathrm{Pa}$ (for glycerol, $P_{\sigma}=1086 \mathrm{~Pa}$ ), which is negligible compared to the pressure of the process.

Heat exchange and mass exchange processes for a single droplet of multi- component fuel could be described by the following equation taking into account heat exchange by convection $Q_{c}$ and $Q_{r}$ radiation:

$\mathrm{Q}(\mathrm{t})=\mathrm{Q}_{\mathrm{c}}(\mathrm{t})+\mathrm{Q}_{\mathrm{r}}(\mathrm{t})=\mathrm{q}(\mathrm{t}) \cdot \mathrm{S}_{\mathrm{d}}(\mathrm{t})$

where $q(t)$ is the heat flux, $S_{d}$ is droplet surface. Taking into consideration the spherical form of the droplet with $r_{d}$ radius: $S_{d}=4 \pi\left(r_{d}\right)^{2} . Q_{c}$ could be described by Newton-Richman rule which states that the amount of heat transferred by convection heat transfer is directly proportional to the temperature difference between the surface of the droplet, $T_{d}$, and the environment, $T_{a}$. Thus,

$Q_{c}(t)=4 \pi \cdot r_{d}^{2} \cdot h_{c}\left(T_{a}-T_{d}\right) \cdot d t$

where $h_{c a}$ is the convective heat transfer coefficient from the ambient air in the chamber to the droplet. The irradiative part, $Q_{r}$, could be described by:

$$
Q_{r}=\sigma . S_{d} \frac{T_{d}^{4}-T_{a}^{4}}{\frac{1}{\varepsilon_{d}}+\frac{s_{d}}{S_{a}}\left(\frac{1}{\varepsilon_{a}}-1\right)}
$$

where the Stefan-Boltzmann constant, $\sigma=5.67 \cdot 10^{-8} \mathrm{~W} /\left(\mathrm{m}^{2} \cdot \mathrm{K}^{4}\right), \varepsilon_{a}, \varepsilon_{d^{-}}$are ambiance and droplet emissivity's values respectively, $S_{a}$ is the effective ambiance surface.

The heat flow q adequate calculation is very difficult according to applied experimental conditions as the furnace walls temperatures are not uniform. So, the temperature field of the oxidizing medium around the droplet is not uniform. Therefore, indirect heat flow determination using experimental data will be applied.

Using energy conservation law, the required heat for droplets evaporation, according to second assumption, equals the right part of Eq. (5). Thus, the heat balance equation is of the form:

$Q(t)=q(t) S_{d}=-\dot{m}_{l}(t) L(T(t))$ where $L$ is the CG-HFO fuel evaporation latent heat is the CG-HFO fuel droplet evaporating flow which consists of two components: a) directed outside the droplet and b) directed inside the gas-activator bubbles contained in the droplet:

$\dot{m}_{l}=\dot{m}_{l, o u t}+\dot{m}_{l, \text { in }}$

Assuming that:

$\xi \frac{\dot{m}_{l, o u t}}{S_{d}}=\frac{\dot{m}_{l, i n}}{n \cdot S_{b}}$

where $\xi$ is a dimensionless factor, $\mathrm{n}$ is the gasactivator bubbles number inside the droplet and $S_{b}=4 \pi\left(r_{b}\right)^{2}$ is the bubble surface, $\mathrm{r}_{\mathrm{b}}$ being the bubble radius. So, Eq. (9) could be written as follows:

$\dot{m}_{l}=\left(1+\xi \cdot \frac{n \cdot S_{b}}{S_{d}}\right) \cdot \dot{m}_{l, \text { out }}$

Thus, the droplet volume consists of liquid fraction volume $V_{l}=\frac{m_{l}}{\rho_{l}}$ and the total volume of bubbles:

$V_{d}=\frac{m_{l}}{\rho_{l}}+n \cdot \frac{4}{3} \cdot \pi \cdot r_{b}^{3}=>\frac{4}{3} \cdot \pi \cdot r_{d}^{3}(t)=\frac{m_{l}(t)}{\rho_{l}(T(t))}+n \cdot \frac{4}{3} \cdot \pi \cdot r_{b}^{3}(t)$

According to $6^{\text {th }}$ assumption the bubbles volume is described by ideal gas

equation of state:

P.n. $V_{b}=\left(\frac{m_{g}}{\mu_{g}}+\frac{m_{v}}{\mu_{v}}\right) \cdot R \cdot T(t)$

where $\mathrm{P}$ is the ambiance pressure, $m_{g} \mu_{g}, m_{v}, \mu_{v}$ are the mass and molecular mass of the gas - activator and CG-HO fuel vapor in the bubbles respectively.

By integrating Eq. (11) the time dependence of CG$\mathrm{HO}$ fuel droplet mass is:

$$
m_{v}(t)=m_{v}(0)-\int_{0}^{t} \xi \cdot \frac{n \cdot r_{b}^{2}}{r_{d}^{2}} \cdot \dot{m}_{l, o u t} \cdot d \tau
$$

Then, the bubble radius could be determined by substituting Eq. (10) in Eq. (9) with taking into consideration Eq. (12):

$$
r_{b}^{3}(t)=\frac{3}{4 \cdot \pi \cdot n} \cdot \frac{R \cdot T}{P}\left(\frac{m_{g}}{\mu_{g}}+\frac{1}{\mu_{v}} \cdot\left[m_{v}(0)-\int_{0}^{t} \xi \frac{n \cdot S_{b}(\tau)}{S_{d}(\tau)} \cdot \dot{m}_{l, \text { out }} d \tau\right]\right)
$$

As the experimental setup allows measuring $T(t), n$ and $\dot{m}_{l, \text { out }}$ the bubble radius could traced as a function of time. Then, using Eqs (12) and (15) the CG-HFO 
fuel droplet $r_{d}$ could be determined:

$r_{d}^{3}=\frac{3}{4 \pi} \frac{m_{l}(t)}{\rho_{l}(T(t))}+n \cdot r_{b}^{3}(t)$

Moreover, the heat flow could be determined according to Eq. (8):

$q(t)=-\frac{\dot{m}_{l}(t) L(T(t))}{S_{d}}$

The characteristics of droplet combustion are controlled by the physical processes associated with heating and evaporation of the liquid droplet. Fundamentally, the droplet evaporation process constitutes two events occurring in tandem.

\section{APPLICATION}

In order to verify the applicability of the proposed model methane as gas- activator is chosen with the emulsified CG-HFO fuel. The initial droplet radius, mass and temperature are $r_{d}(0)=0.0025 \mathrm{~m}, m_{d}(0)=40.10^{-6} \mathrm{~kg}, \quad$ and $T_{d}(0)=293 \mathrm{~K}$ respectively. The methane gas inclusions (bubbles) volume in the CG-HFO fuel droplet is 0.12 of droplet volume, the initial gas bubbleactivator radius is, $\mathrm{r}_{\mathrm{b}}=1.197 .10^{-4} \mathrm{~m}$. Thus, the bubbles number is, $\mathrm{n}=1093$ and, $\xi=2.5$. The CG-HFO fuel droplet time dependence temperature was found experimentally to be described by the equation:

$T_{d}(t)=-10^{-6} \cdot t+0.0012 . t^{2}-0.0583 . t+293$

The CG-HFO fuel droplet mass with bubbles time dependence was found experimentally to be described by equations:

$m_{l}(t)=-3 \cdot 10^{-17} \cdot t^{4}+10^{-13} \cdot t^{3}-10^{-10} \cdot t^{2}+10^{-8} \cdot t+4 \cdot 10^{-5}$

Assume that buckling occurs at time when $r_{d}(\tau)=r_{d \text { max }}$, then $\frac{d r_{d}}{d t}=0 . \quad$ Program was developed for the numerical simulation of the behavior of a droplet up to the point of stability loss.

To perform a numerical experiment using the developed program, specified properties of the test fuel and used gas activator, the amount of gas activator bubbles should be given. The program generates a file with the result, which specifies: the process $(t, s e c)$; process temperature $(\mathrm{T}, \mathrm{K})$, a droplet mass $(\mathrm{m}, \mathrm{kg})$, the droplet radius $(r, m)$ and allows to obtain the data in graphical form. As an example, Figure 5 shows the dependence of the relative change of the droplet radius as a function of temperature. As shown in Figure 3, the effect of the active foaming confirmed, i.e. increasing the diameter of the droplets at the initial stage of heating the droplets, which in turn increases the rate of evaporation of the droplet by increasing the external heat transfer. The enlarged beginning part of Figure 5 is given in Figure 6.

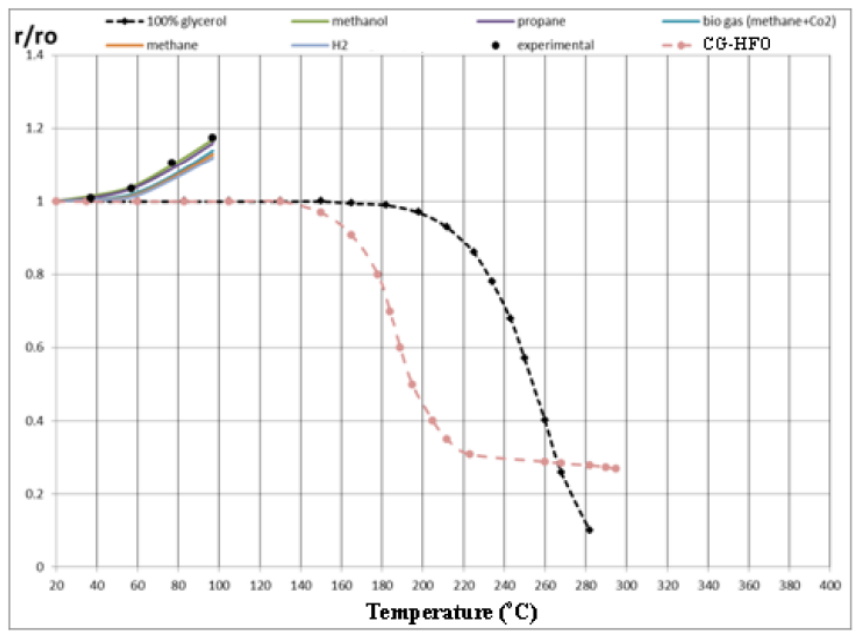

Figure 5: Temperature droplet radius dependence.

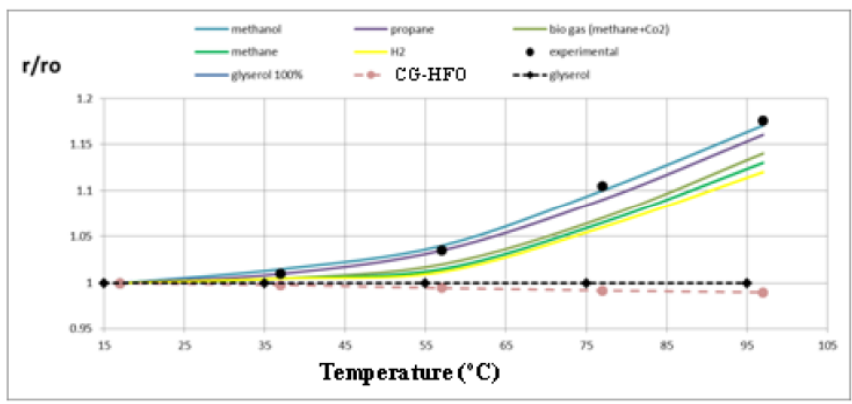

Figure 6: Enlarged temperature droplet radius dependence.

\section{CONCLUSIONS}

Analysis of the obtained results allows the following conclusions:

1. The nature of the ignition and combustion of $\mathrm{CG}_{(1-\mathrm{X})}-\mathrm{HFO}$ X does not vary significantly with increasing $\mathrm{HFO}$ concentrations.

2. The pre-ignition processes in the $\mathrm{CG}_{(1-\mathrm{X})}-\mathrm{HFO}_{\mathrm{X}}$ fuel droplet differ significantly from those described in the literature processes for preignition pure fuels droplet because of the foaming ability of CG.

3. Numerical modeling of the foamed CG-HFO droplet evaporation process confirmed that, foaming is connected with heating of a droplet and with bulking of gas bubble. 
4. Within the limits of the accepted model of calculations, it is possible to estimate the contribution, of the gas phase and methanol vapors evaporating from CG, to bubble expansion. The role of methanol vapors in the investigated range of temperatures is no more than $10 \%$.

5. It is established that influence of the substanceactivator structure is not essential for the time of droplet maximum diameter achievement. This effect will be hopefully studied in detail in the near future. However the basic time of achievement of the droplet maximum diameter is observed during application of hydrogen as substance-activator.

6. CG-HFO droplets got during modeling of process of the evaporation initial stage confirm the basic features of CG-HFO droplets behavior and give the grounds for the formulation of the scientifically-proved recommendations about the organization of CG-HFO droplets burning in the combustion chambers, namely, for a choice of gaseous substance-activator and installation of devices for trapping and re-burning of large conglomerates in the combustion chambers or the organization of a vertical combustion mode.

\section{REFERENCES}

[1] Kovacs A. Aspects of refining biodiesel byproduct glycerin. Petroleum \& Coal 2011; 53 (1): 91-97.

[2] Kocsisova T, Cvengros J. G-phase from methyl ester production - splitting and refining. Petroleum and Coal, 2006; 48(2): 1-5.

[3] Kolesárová N, Hutňan M, Bodík I, \& Špalková V. Utilization of biodiesel by-Products for biogas production. Journal of Biomedicine and Biotechnology 2011; 1-15. https://doi.org/10.1155/2011/126798

[4] Xiao Y, Xiao G, Varma, A. A Universal Procedure for Crude Glycerol Purification from Different Feedstocks in Biodiesel Production: Experimental and Simulation Study. Industrial \& Engineering Chemistry Research 2013; 52(39): 1429114296.

https://doi.org/10.1021/ie402003u

[5] Singhabhandhu A, Tezuka T. A perspective on incorporation of glycerin purification process in biodiesel plants using waste cooking oil as feedstock. Energy 2010; 35(6): 24932504.

https://doi.org/10.1016/j.energy.2010.02.047

[6] Mize HE, Lucio AJ, Fhaner CJ, Pratama FS, Robbins LA, Karpovich DS. Emulsions of Crude Glycerin from Biodiesel Processing with Fuel Oil for Industrial Heating. Journal of Agricultural and Food Chemistry, 2013; 61(6); 1319-1327. https://doi.org/10.1021/jf304883t

[7] Eaton SJ, Harakas GN, Kimball RW, Smith JA, Pilot KA, Kuflik MT, Bullard JM. Formulation and Combustion of Glycerol-Diesel Fuel Emulsions. Energy \& Fuels 2014; 28(6): 3940-3947.

https://doi.org/10.1021/ef500670d
Leng L, Yuan X, Zeng G, Chen X, Wang H, Li H, Fu L, Xiao Zh, Jiang L, Lai C. Rhamnolipid based glycerol-in-diesel microemulsion fuel: Formation and characterization. Fuel 2015; 147: 76-81.

https://doi.org/10.1016/j.fuel.2015.01.052

[9] Asdrubali F, Cotana F, Rossi F, Presciutti A, Rotili A, Guattari C. Life Cycle Assessment of New Oxy-Fuels from BiodieselDerived Glycerol. Energies, 2015; 8(3): 1628-1643. https://doi.org/10.3390/en8031628

[10] Junior FSC, Alves JCS, Cavalcante FSA, de Lima LC Parameters Analysis of the Assisted Combustion of Residual Biodiesel Glycerol. International Transaction Journal of Engineering, Management, \& Applied Sciences \& $\begin{array}{llll}\text { Technologies } & 2012 ; & 3(4): & 455-465\end{array}$ http://TuEngr.com/V03/455-465.pdf

[11] Chertkov Ya. B, Spirkin V. (1974). The use of jet fuels in aviation, Transport, Moscow.

[12] Spalding DB. Convective mass transfer an introduction, Edward Arnold Ltd., London 1963.

[13] Spalding DB. Combustion and mass transfer, Imperial College of Science \& Technology, London, England \& Purdue University, Indiana, USA, Pergamon Press Ltd 1979.

[14] Macleod DB. The kinetic theory of evaporation. Transaction of the Faraday society $1925 ; 20: 525-543$. https://doi.org/10.1039/tf9252000525

[15] Shuleikin VV. The kinetic theory of evaporation. Russian Journal of Physical Chemistry of Gases (Leningrad University) 1926; 58: 527-540. (in Russian)

[16] Shuleikin VV. Sea Physics. Moscow, Nauka 1968.

[17] Lewis B, Pease RN, Taylor HS. (eds). Combustion Processes. Oxford University Press, London; York, Pa. printed 1956 https://doi.org/10.1515/9781400877027

[18] Ol'shanskii SV. The Calculation of Droplet's Vertical Motion that Evaporates under the Sreznevsky Law. Naukovi visti NTUU - KPI, 2011; (4): 149-163.

[19] Dwyer OE. Boiling Liquid-Metal Heat Transfer, American Nuclear Society, La Grange Park, Illinois 1976.

[20] Boyadjiev C, Boyadjiev B. On the non-stationary evaporation kinetics. International Journal of Heat and Mass Transfer 2003; 46(9): 1679-1685. https://doi.org/10.1016/S0017-9310(02)00467-2

[21] Kuznetsov D, Moiseev M, Zhukov V. Studying the development of evaporation front interface in Freon R21 at non-stationary heat release. MATEC Web of Conferences 2015; 23: 01022. https://doi.org/10.1051/matecconf/20152301022

[22] Volmer R, Eckert J, Füldner G, Schnabel L. Evaporator development for adsorption heat transformation devices Influencing factors on non-stationary evaporation with tubefin heat exchangers at sub-atmospheric pressure. Renewable Energy 2017; 110: 141-153. https://doi.org/10.1016/j.renene.2016.08.030

[23] Wang F, Yao J, Yang S, Liu R, Jin J. A new stationary droplet evaporation model and its validation. Chinese Journal of Aeronautics, 2017; 30(4): 1407-1416. https://doi.org/10.1016/j.cja.2017.06.012

[24] Colburn AP, Drew TB. The Condensation of Mixed Vapours. Trans. Am. Inst. Chem. Engnrs 1937; 33: 197-215

[25] Luchak G, Langstroth GG. Applications of diffusion theory to evaporation from droplets and flat surfaces, Canadian Journal of Research, 1950; 28a(6): 574-579. https://doi.org/10.1139/cjr50a-048

[26] De Oliveira MM, Dickman R. How to simulate the quasistationary state. Physical Review E, 2005; 71(1): https://doi.org/10.1103/PhysRevE.71.016129

[27] Dickman R, Vidigal R. Quasi-stationary distributions for stochastic processes with an absorbing state. Journal of 
Physics A: Mathematical and General 2002; 35(5): 11471166.

https://doi.org/10.1088/0305-4470/35/5/303

[28] Burger M, Schmehl R, Prommersberger K, Schäfer O, Koch $\mathrm{R}$, Wittig S. Droplet evaporation modeling by the distillation curve model: accounting for kerosene fuel and elevated pressures. International Journal of Heat and Mass Transfer 2003 46(23): 4403-4412. https://doi.org/10.1016/S0017-9310(03)00286-2

[29] Popov S, Melling A, Durst F, Ward CA. Apparatus for investigation of evaporation at free liquid-vapour interfaces. International Journal of Heat and Mass Transfer 2005; 48(11): 2299-2309. https://doi.org/10.1016/j.ijheatmasstransfer.2004.10.038

[30] Hołyst R, Litniewski M, Jakubczyk D, Kolwas K, Kolwas M, Kowalski K, Zientara M. Evaporation of freely suspended single droplets: experimental, theoretical and computational simulations. Reports on Progress in Physics 2013; 76(3): 034601. https://doi.org/10.1088/0034-4885/76/3/034601

[31] Kotake S, Okazaki T. Evaporation and combustion of a fuel droplet. International Journal of Heat and Mass Transfer 1969; 12(5): 595-609.

https://doi.org/10.1016/0017-9310(69)90041-6

[32] Abramzon B, Sirignano WA. Droplet vaporization model for spray combustion calculations. International Journal of Heat and Mass Transfer 1989; 32(9): 1605-1618. https://doi.org/10.1016/0017-9310(89)90043-4
[33] Sazhin S, Kristyadi T, Abdelghaffar W, Heikal M. Models for fuel droplet heating and evaporation: Comparative analysis. Fuel 2006; 85(12-13): 1613-1630. https://doi.org/10.1016/i.fuel.2006.02.012

[34] Sazhin SS. Advanced models of fuel droplet heating and evaporation. Progress in Energy and Combustion Science 2006; 32(2): 162-214.

https://doi.org/10.1016/j.pecs.2005.11.001

[35] Sazhin SS, Al Qubeissi MA. Modelling of automotive fue droplet heating and evaporation: mathematical tools and approximations. Journal of Physics: Conference Series 2016; 727: 012015.

https://doi.org/10.1088/1742-6596/727/1/012015

[36] Villasenor R, Garcia F. An experimental study of the effects of asphaltenes on heavy fuel oil droplet combustion. Fuel 1999; 78(8): 933-944.

https://doi.org/10.1016/S0016-2361(99)00010-1

[37] Ocampo-Barrera R, Villasenor R, Diego-Marin A. An experimental study of the effect of water content on combustion of heavy fuel oil/water emulsion droplets. Combustion and Flame 2001; 126(4): 1845-1855. https://doi.org/10.1016/S0010-2180(01)00295-4

[38] Karmakar S, Som SK, Rao DCK. Combustion of Multicomponent Fuel Droplets. Droplets and Sprays 2017; 77 114.

https://doi.org/10.1007/978-981-10-7449-3 4

DOI: http://dx.doi.org/10.31875/2410-2199.2018.05.5

(C) 2018 Soulayman and Youssef; Zeal Press.

This is an open access article licensed under the terms of the Creative Commons Attribution Non-Commercial License (http://creativecommons.org/licenses/by-nc/3.0/) which permits unrestricted, non-commercial use, distribution and reproduction in any medium, provided the work is properly cited. 